\title{
MAXIMIZATION OF LENGTH AND LIFETIME OF CLUSTERED INDUSTRIAL AUTOMATION NETWORK
}

\author{
R. Nagarajan, R. Dhanasekaran
}

Original scientific paper The main function of industrial automation networks (IANs) is to monitor and control processes. In general, the sensor nodes utilize batteries as an energy source to control processes. The clustered IAN aims at maximizing the lifetime of the sensor node by improving the energy efficiency. The proposed system is targeted for utilization of the long distance wireless transmission radio modules where the energy distribution needs to be reduced to a greater extent. This paper presents the impact of adopting sleeping mechanisms in transmitting a physical variable from the industrial area to the base station where the controller is present. The number of transmissions that occurs due to the application of aggressive sleeping behaviour has been compared to the normal sleeping behavioural approach. The energy spent by the network for communication greatly depends on the number of transmissions. Hence, the network lifetime can be maximized by minimizing the energy spent for transmission.

Keywords: energy efficiency; industrial automation; routers; sensors; WSN; ZigBee

Maksimizacija duljine i trajanja klasterirane mreže industrijske automatizacije

Izvorni znanstveni članak

Osnovna funkcija mreža industrijske automatizacije - IANs (Industrial Automation Networks) je nadzor i upravljanje procesima. Općenito, čvorovi senzora koriste baterije kao izvor energije za upravljanje procesima. Svrha je klasteriranog IAN-a maksimiziranje vijeka trajanja senzorskog čvora poboljšanjem energetske učinkovitosti. Predloženi je sustav namijenjen primjeni radio modula s bežičnim prijenosom na daljinu gdje se razvođenje energije treba znatno smanjiti. U radu se daje prikaz djelovanja primjene prikrivenih (spavajućih) mehanizama u prijenosu fizičke varijable iz industrujskog područja u baznu stanicu gdje postoji regulator. Broj prijenosa zbog primjene agresivnog prikrivenog ponašanja uspoređen je s pristupom uobičajenom prikrivenom ponašanju (sleeping behavioral approach). Energija koju troši komunikacijska mreža uvelike ovisi o broju prijenosa. Prema tome se vijek trajanja mreže može maksimalno produžiti minimiziranjem energije potrošene za prijenos.

Ključne riječi: industrijska automatizacija; senzori; učinkovitost energije; usmjernici; WSN; ZigBee

\section{Introduction}

In the present scenario, the wireless sensor networks (WSNs) have become more popular because of the smaller size of the devices and their easy deployment in different industries for different applications [1]. WSNs consist of sensor nodes that are distributed throughout the process industry area. These sensor nodes sense, process, and communicate data to the base station [2]. WSN has been effectively implemented in home automation, monitoring of environmental conditions, remote patient monitoring, and so on [3]. In general, industrial automation can be achieved through wired networks by involving a standard $4 \div 20 \mathrm{~mA}$ electrical system. Traditional industrial automation network (IAN) involves wired communication system in which the programmable logic controller (PLC) or distributed control system (DCS) communicates with the sensors to collect the process-related data. For providing the control, the PLC or DCS acts on the physical variables measured by issuing the commands or signals that activate relays, solenoid valves, motors, and actuators. In a previous work, the authors suggested relay model-based industrial monitoring and controlling network, which contained many sensor nodes that measured the value of physical parameters, such as temperature, pressure, flow, level, density, etc., and transmitted them to the central control room through intermediate nodes called routers [4].

The relay model was suggested for extending the network length, but this method failed to provide the desired results in the case of any malfunction in the intermediate nodes or routers. In the present study, the proposed clustered IAN (CIAN) overcomes the limitations of the relay model by replacing the XBee-PRO router with Xstream 2.4 GHZ, 10 mile LOS range OEM RF module. The deployment of WSN for real-time applications is hindered because of the limited energy backup of the sensor [5]. The energy backup can be enriched by attaching renewable energy sources with the sensor nodes, which improves the IAN lifetime [6]. The power consumed by the sensor node to establish the transmission may get changed based on the distance between the sensor node and base station. The power consumed by the sensor node is directly proportional to the distance between the sensor node to cluster head and cluster head to the base station, which also impacts the network lifetime [7]. In relay or multihop transmission model, intermediate routers have been used to extend the length of the network, which may have an impact on power consumption as well as network lifetime [8].

Another way to maximize the network lifetime is to adopt appropriate sleeping mechanisms. Sleeping mechanisms have been implemented to reduce the energy consumption and improve the network lifetime. Energy efficiency can be improved by turning on and off the radio transceiver according to a wake up schedule of a sensor node [9].The sensor node adopts either normal or aggressive sleeping behaviour depending on the assigned duty cycle. Thus, this study proposes a CIAN model and aims to present the impact of adopting sleeping mechanisms in data transmissions from the industrial area to the base station and compare the number of transmissions due to aggressive sleeping behaviour to that of the normal sleeping behavioural approach.

The rest of the paper is organized as follows. Section 2 deals with the related work in this domain and Section 3 
explains the implementation of the proposed CIAN. Section 4 deals with the simulation details to maximize the lifetime of an IAN. Section 5 details the results and discussion of the study, and Section 6 provides the conclusion of the paper and recommendations for practitioners when selecting an appropriate approach to extend the length and maximize the lifetime of a network.

\section{Related work}

In the previous work, the authors developed the prototype for relay model-based ZigBee IAN, which can communicate wirelessly with the central control panel through ZigBee protocol to receive control information and send sensor data [10]. The prototype of relay modelbased ZigBee IAN was implemented to analyse the feasibility of introducing wireless technology and extending the length of the network in process control applications [11]. In general, transmitters, sensors, and final control elements were distributed in the industrial area over a long distance. The ZigBee-enabled sensor node transmitted the measured value to the ZigBee coordinator placed at the central control room through intermediate routers. The ZigBee coordinator was interfaced with the personal computer through RS232 serial port [12]. The graphic user interface (GUI) has been developed using Lab view building block that can be used to display the status of the physical parameters measured through the sensor nodes. This allows the human operator to evaluate the performance of a process and also initiate the corrective actions for quick recovery during hostile environmental conditions. The historian module has been incorporated to record all significant parameters and display them in the form of suitable graphs. This can be useful in preventing the occurrence of critical events in the field by discovering the reasons for their occurrence. However, the limitation of this method is that each sensor has to transmit the data to the base station through many intermediate routers. Hence, a failure in intermediate routers can disrupt the data transmission process.

Yan et al. (2011) suggested utilizing the distributed fibre sensors (DFS) to analyse the physical parameter along with the fibre link. This arrangement may be capable of transmitting data ranging from hundreds of meters to tens of kilometres. The DFS link is located at the centre of the sensor field and can cover a certain area. The two WSN fields are filled with randomly scattered nodes, and the communication between these nodes depends on the requirements of the application. DFS has to be powered for data processing, which may use one end of the DFS as the base station for all WSN nodes [13]. This may lead to increased cost, time of implementation, and maintenance. The proposed model eliminates this problem by replacing the distributed fiber sensors with Xstream 2.4 GHZ, 10 mile LOS range OEM RF module.

\section{Implementation of CIAN}

The data transmission methods can be classified into direct and indirect methods. In the direct method, the sensor node collects and transmits the data directly to the base station; the path from the sensor node to the base station is called multi-hop path. If the sensor node is far away from the base station, the battery power can drain quickly due to the long distance that needs to be covered for the data transmission [14]. Another disadvantage is that the data may not be sent to the base station if the sensor node is too far away. The indirect transmission means that the sensor nodes send their collected data to intermediate nodes that are also called relay nodes. This relay node subsequently forwards the aggregated data to the base station. However, in cluster-based transmission, the data is sent to the base station through the cluster head. The cluster means a group of sensor nodes in which one of the nodes acts as the cluster head [15]. The nodes transmit the data to the base station through the cluster head. The sensing nodes are at a different location from the base station that causes different amount of energy dissipation. Fig. 1 shows the function of cluster-based data transmission approach.

\section{BASE STATION}
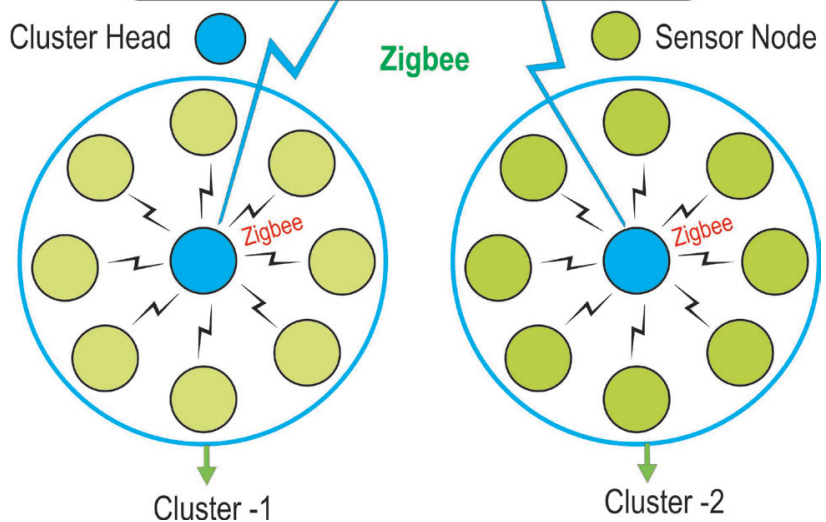

Figure 1 Cluster based data transmission

The prototype model of CIAN can be implemented by establishing the hardware architecture involving sensors, Advanced RISC Machines (ARM) processor, transceiver, liquid crystal display (LCD), and power source [16]. The sensors produce analog signals according to the changes occurring in the process. Subsequently, the analog signals are converted into digital signals using analog-to-digital converters [17] that are then sent to the ARM processor for further processing. The ARM processor is used to process the data and control other accessories present in the sensor node. XBee-PRO radio module acts as a transceiver and establishes the communication between the sensor node [18] and $\mathrm{X}$ stream module, and then to the central control room. In addition, each sensor node is provided with LCD that displays the current status of a physical variable involved in the process. Fig. 2 shows the prototype model of CIAN.

Each sensor is provided with a regulated power supply and a serial port to record the status of the physical variables. Power on all the sensors, cluster heads, and coordinator then observe the results in GUI. The program written in Embedded $\mathrm{C}$ considerably simplifies working with XBeePRO Module [19]. A user-friendly GUI [20] manages the entire communication process to allow remote monitoring of physical parameters. GUI is designed to indicate and monitor all physical parameters 
involved in the process. All the sensors, routers, and coordinator are powered, and the GUI is connected through a serial port to initiate the communication process.

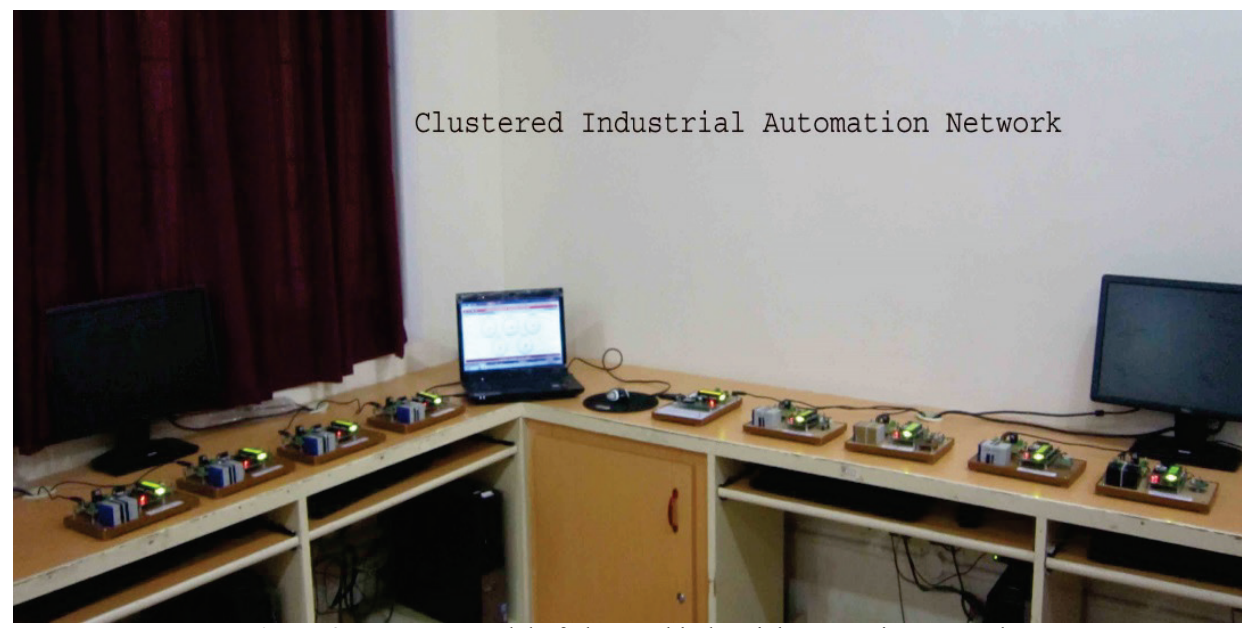

Figure 2 Prototype model of clustered industrial automation network

\section{Maximization of the lifetime of CIAN - simulation}

This work aims at maximizing the lifetime of a network by optimizing the energy spent by the nodes present in the network [21]. Simulation has been carried out in the Matlab environment to investigate the time taken for transmission, the number of samples transmitted, and the energy spent for the transmission of samples. Based on the investigation, recommendations could be provided to maximize the lifetime of a network. The monitoring region refers to the network area where 100 sensor nodes are scattered randomly and uniformly in a square of $100 \mathrm{~m}$. According to the program, 100 nodes are created with an initial energy of $0,001 \mathrm{~J}$ for each node. The sink is placed at the centre of the square area where the 100 nodes are generated. The nodes that are within the range of $25 \mathrm{~m}$ form a random cluster as shown in Fig. 3.

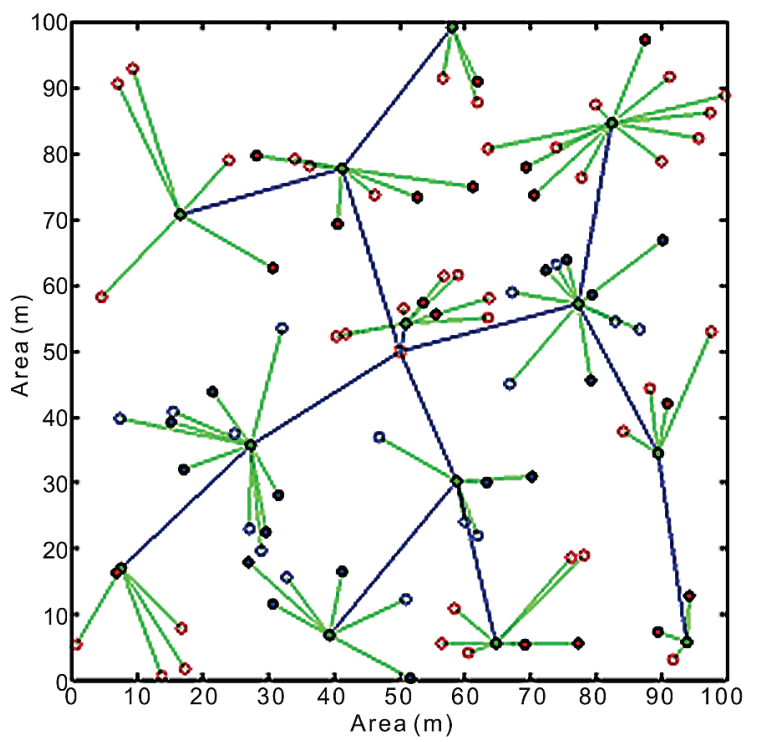

Figure 3 Cluster formation

The head node of each cluster is called a cluster head. The nodes in the network are represented in three different colours. The cluster heads are represented with green colour. The derived cluster head data from the cluster members are transmitted to the sink [22]; this is indicated by the blue line. The nodes that work in normal sleeping behaviour are represented by red colour, and the remaining nodes that work in aggressive sleeping behaviour are represented by blue colour. Fig. 4 denotes the transmission time of each node. The cluster heads transmit the data to the sink continuously.

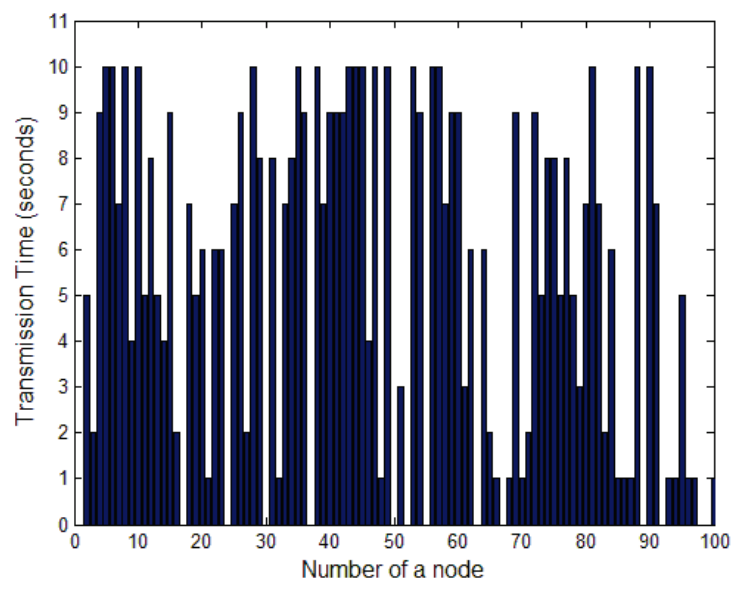

Figure 4 Number of nodes vs. transmission time

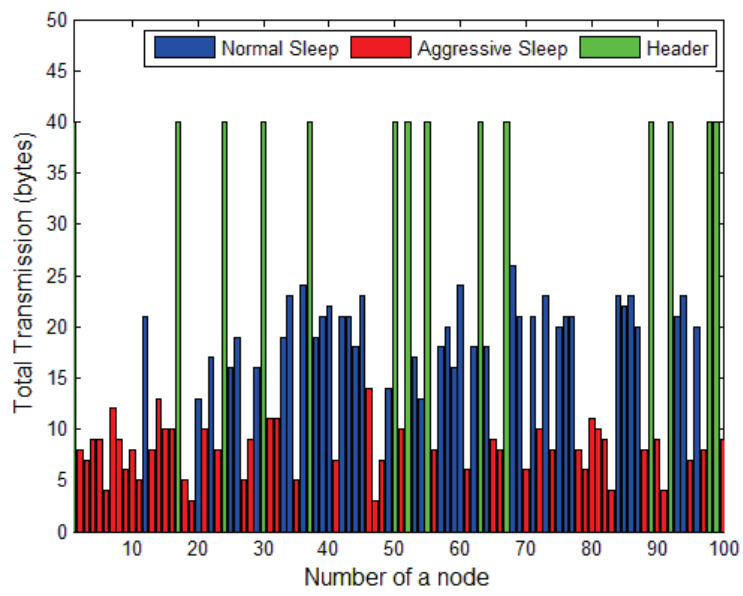

Figure 5 Node vs. total transmission

Hence, the transmission time of the cluster head is highly comparable to that of the other cluster members (shown in green colour in Fig. 5). The sensor nodes must 
be put into sleep mode if they are not required to transmit or receive data. Fig. 5 indicates the number of transmissions of each node under the control of sleeping behaviour. Sleeping modes could be implemented to reduce the energy spent by the node, which leads to the improvement in the lifetime of the network.

When a node does not have data to send, it follows the basic sleeping behaviour policy [23]. In this method after sending a data, the node may go to sleep for some time and then again start transmitting. The cluster head (green colour) is required to send the data packets to the sink all the time as compared to other cluster members. Hence, the number of transmissions by a cluster head remains high. The nodes that work in the normal sleeping behaviour (blue colour) periodically send the data packets to the cluster head. For these nodes, the number of transmissions remains high. The nodes that work in aggressive sleeping behaviour (red colour) send the data to the $\mathrm{CH}$ during the occurrence of the event. Therefore, the number of transmissions is less than that of the normal sleeping mode.

Fig. 6 indicates the energy spent by the node for transmission. This plot shows the energy comparison between the initial node energy and node energy after using the sleeping mechanism.

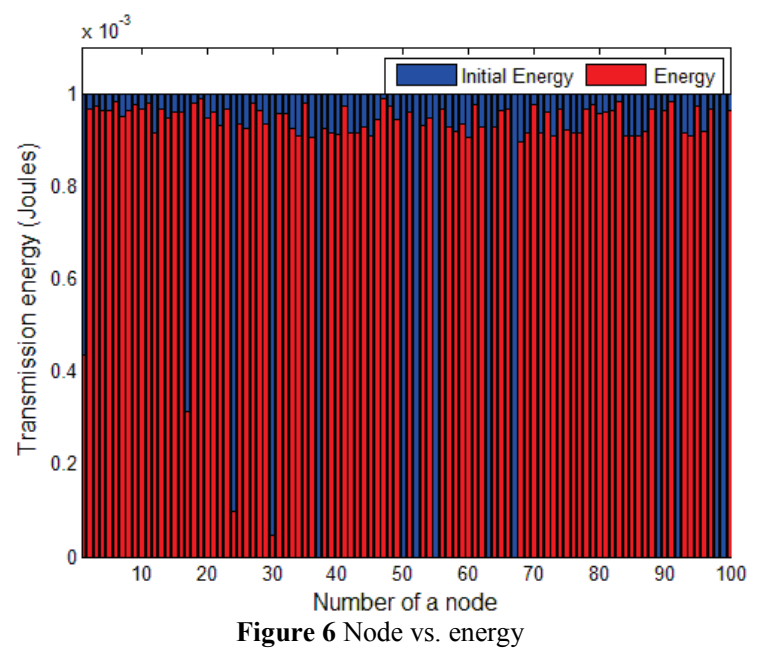

The energy usage is minimized by choosing the appropriate sleeping mechanism and the duty cycle control in a distributed and autonomous manner [24]. The initial energy (blue line) of each node is $0,001 \mathrm{~J}$. After the transmission and initiation of the sleeping modes, the energy usage (red line) of each node is minimized.

\section{$5 \quad$ Results and discussions}

The prototype model of CIAN has been implemented using XBEE PRO Radio module for sensor node [25], and Xstream $2.4 \mathrm{GHZ} 10$ mile LOS range OEM RF module [26] for cluster head and coordinator. The applicability of introducing ZigBee technology to transmit the data over a long distance in CIAN is analysed. The process parameters were altered, and the functionality of the prototype was observed by noting the transmitted and received values of few parameters. The transmitted values of the sensors are noted through LCD. The results obtained are shown in Figs. 7 and 8 that indicate the transmitted value, which is almost closer to the received value. Hence, the CIAN can be implemented in any process industry to transmit data over a long distance.

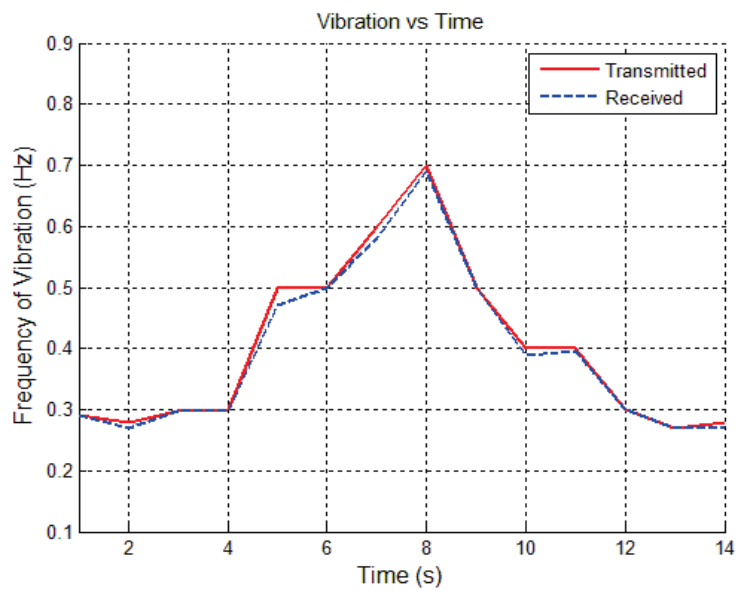

Figure7 Status of transmission and reception of humidity

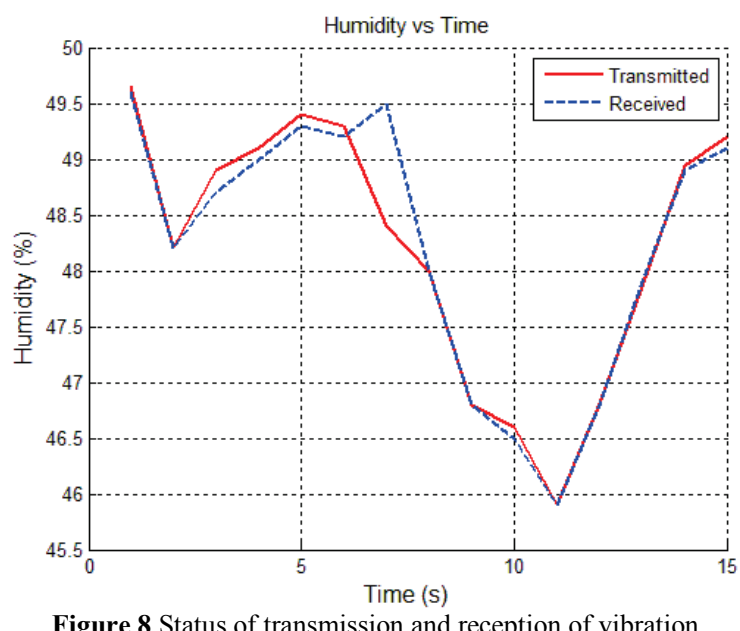

Figure 8 Status of transmission and reception of vibration

An important issue to be addressed while implementing CIAN is the lifetime maximization of the network, which can be achieved by reducing the power consumed by the sensor nodes [27]. Figs. $4 \div 6$ show the time taken, the number of transmissions made, and energy spent by each node for transmission to its cluster, respectively. The energy spent by the cluster heads for the transmission is maximum compared to that of all other nodes because the cluster heads communicate with the parameters of the process variables to the base station continuously.

\section{Conclusion}

The prototype model of CIAN has been developed by employing XBee PRO radio modules, Xstream 2.4 GHZ 10 mile LOS range OEM RF module, and with allied circuit that overcomes the limitations of relay model based ZigBee IAN. The implementation of this model and analysis of its performance conclude that the physical length of an IAN can be improved to a greater extent. Hence, the cost and time required for erection and power consumption would be reduced. The results shown above highly recommend CIAN instead of the traditional wired IAN. However, the limitation of the proposed method is that if the cluster head fails, the transmission of the 
required data to the base station may also fail. This can be eliminated by introducing backup cluster head for each cluster head in the network, and appropriate mechanism should be provided to activate the backup cluster head when the cluster head fails to transmit the data to the base station. The obtained simulation results conclude that the power consumed by the sensor nodes can be reduced by choosing the appropriate sleeping behaviour, which leads to the maximization of the network lifetime.

\section{References}

[1] Yao, L.; Zeng, F. Maximum set covers based energy conservation scheme in wireless sensor networks. // Technical Gazette. 21, 4(2014), pp. 733-739.

[2] O'Connell, E.; Healy, M.; O'Keeffe, S.; Thomas Newe, T.; Lewis, E. A Mote Interface for Fiber Optic Spectral Sensing With Real-Time Monitoring of the Marine Environment. // IEEE Sensors J. 13, 7(2013), pp. 26192625. DOI: 10.1109/JSEN.2013.2258760

[3] Wang, Z.; Kravtsov, K.; Chang, J.; Prucnal, P. R. Sensor Data Transmission Overlay on Gigabit Passive Optical Networks. // J. Opt. Commun. Netw. 3, 7(2011), pp. 553558. DOI: $10.1364 / \mathrm{JOCN} .3 .00055$

[4] Barac, F.; Caiola, S.; Sisinni, E.; Zhang, T. Channel Diagnostics for Wireless Sensor Networks in Harsh Industrial Environments. // IEEE Sensors J. 14, 11(2014), pp. 3983-3994. DOI: 10.1109/JSEN.2014.2356972

[5] Magno, M.; Boyle, D.; Brunelli, D.; O’Flynn, B.; Popovici, E.; Benini, L. Extended Wireless Monitoring Through Intelligent Hybrid Energy Supply. // IEEE Trans. Ind. Electron. 61, 4(2014), pp. 1871-1881. DOI: 10.1109/TIE.2013.2267694

[6] Wang, N.; Zhu, Y.; Wei, W.; Chen, J.; Liu, S.; Li, P.; Wen, Y. One-to-Multipoint Laser Remote Power Supply System for Wireless Sensor Networks. // IEEE Sensors J. 12, 2(2012), pp. 389-396. DOI: 10.1109/JSEN.2011.2161465

[7] Hoang, D. C.; Yadav, P.; Kumar, R.; Panda, S. K. RealTime Implementation of a Harmony Search AlgorithmBased Clustering Protocol for Energy-Efficient Wireless Sensor Networks. // IEEE Trans. Ind. Informat. 10, 1(2014), pp. 774-783. DOI: 10.1109/TII.2013.2273739

[8] Ming, M.; Yuanyuan, Y.; Miao, Z. Tour Planning for Mobile Data-Gathering Mechanisms in Wireless Sensor Networks. // IEEE Trans. Veh. Technol. 62, 4(2013), pp. 1472-1483. DOI: 10.1109/TVT.2012.2229309

[9] Howitt, I.; Neto, R.; Wang, J.; Conrod, J. M. Extended energy model for the low rate WPAN. // Proceedings of the IEEE Int. Conference on Mobile Adhoc and Sensor Systems / Washington, 2005, pp. 322-330. DOI: 10.1109/MAHSS.2005.1542815

[10] Suryadevara, N. K.; Mukhopadhyay, S. C. Wireless Sensor Network Based Home Monitoring System for Wellness Determination of Elderly. // IEEE Sensors J. 12, 6(2012), pp. 1965-1972. DOI: 10.1109/JSEN.2011.2182341

[11] Nagarajan, R.; Dhanasekaran, R. Wire free Relay Model based Industrial Monitoring and Control. // IJAER. 10, 5(2015), pp. 4360-4364.

[12] Sun, X.; Xu, K.; Shen, X.; Li, Y.; Dai, Y.; Wu, J.; Lin, J. New Hierarchical Architecture for Ubiquitous Wireless Sensing and Access with Improved Coverage Using CWDM-ROF Links. // J. Opt. Commun. Netw. 3, 10(2011), pp. 790-796. DOI: 10.1364/JOCN.3.000790

[13] Yan, L. S.; Wei, P. W.; Luo, B.; Li, X.; Liu, J. Modified Energy-Efficient Protocol for Wireless Sensor Networks in the Presence of Distributed Optical Fiber Sensor Link. // IEEE Sensors J. 11, 9(2011), pp. 1815-1819. DOI: 10.1109/JSEN.2010.2104317
[14] Wac, K.; Tsiourti, C. Ambulatory Assessment of Affect: Survey of Sensor Systems for Monitoring of Autonomic Nervous Systems Activation in Emotion. // IEEE Trans. on Affect. Comp. 5, 3(2014), pp. 251-272. DOI: 10.1109/TAFFC.2014.2332157

[15] Han, Z.; Wu, J.; Zhang, J.; Liefeng, L.; Tian, K. A General Self-Organized Tree-Based Energy-Balance Routing Protocol for Wireless Sensor Network. // IEEE Trans. Nucl. Sci. 61, 2(2014), pp. 732-740. DOI: 10.1109/TNS.2014.2309351

[16] Gutiérrez, J. J.; Villa-Medina, J. F.; Aracely LópezGuzmán, A.; Porta-Gándara, M. A. Smartphone Irrigation Sensor. // IEEE Sensors J. 15, 9(2015), pp. 5122-5127. DOI: 10.1109/JSEN.2015.2435516

[17] Schulz, V.; Ebert, H.; Gerlach, G. A Closed-Loop Hydrogel-Based Chemical Sensor. // IEEE Sensors J. 13, 3(2013), pp. 994-1002. DOI: 10.1109/JSEN.2012.2227709

[18] Lambrou, T. P.; Anastasiou, C. C.; Panayiotou, C. G.; Polycarpou, M. M. A Low-Cost Sensor Network for RealTime Monitoring and Contamination Detection in Drinking Water Distribution Systems. // IEEE Sensors J. 14, 8(2014), pp. 2765-2772. DOI: 10.1109/JSEN.2014.2316414

[19] Zhou, B.; Yang, S.; Sun, T.; Grattan, K. T. V. A Novel Wireless Mobile Platform to Locate and Gather Data From Optical Fiber Sensors. // IEEE Sensors J. 15, 6(2015), pp. 3615-3620. DOI: 10.1109/JSEN.2015.2396040

[20] Zhou, B.; Yang, S.; Nguyen, T. H.; Sun, T.; Grattan, K. T. V. Wireless Sensor Network Platform for Intrinsic Optical Fiber pH Sensors. // IEEE Sensors J.14, 4( 2014), pp. 13131320. DOI: 10.1109/JSEN.2013.2294931

[21] Monica, R. M.; Kiran, S.; Shivanand, K.;Varsha, R. N.; George, S. A. A Study on Energy Efficient Routing Protocols in Wireless Sensor Networks. // IJDPS. 3, 3(2012), pp. 311-330. DOI: 10.5121/ijdps.2012.3326

[22] Wang, J.; Yin, Y.; Zhang, J.; Lee, S.; Sherratt, R. S. Mobility based Energy Efficient and Multi-Sink Algorithms for Consumer Home Networks. // IEEE Trans. Consum. Electron. 59, 1(2013), pp. 77-84. DOI: 10.1109/TCE.2013.6490244

[23] Camillò, A.; Nati, M.; Petrioli, C.; Rossi, M.; Zorzi, M. IRIS: Integrated data gathering and interest dissemination system for wireless sensor networks. // Ad Hoc Networks. 11, (2013), pp. 654-671. DOI: 10.1016/j.adhoc.2011.09.009

[24] Anastasi, G.; Conti, M.; Francesco, M. D.; Passarella, A. Energy conservation in wireless sensor networks: A survey. // Ad Hoc Networks. 7, (2009), pp. 537-568. DOl: 10.1016/j.adhoc.2008.06.003

[25] Suryadevara, N. K.; Mukhopadhyay, S. C.; Kelly, S. D. T.; Gill, S. P. S. WSN-Based Smart Sensors and Actuator for PowerManagement in Intelligent Buildings. // IEEE/ASME Trans. Mechatronics. 20, 2(2015), pp. 564-571. DOI: 10.1109/TMECH.2014.2301716

[26] http://www.digi.com/products/Xbee-rf-solutions/modules/ xstream-module

[27] Qiu, Y.; Liu, C. Modelling and stimulation of target tracking and localization in wireless sensor network. // Technical Gazette. 21, 2(2014), pp. 233-238. 


\section{Authors' addresses}

\section{R. Nagarajan}

Department of Electrical and Electronics Engineering,

Syed Ammal Engineering College,

Ramanathapuram, Tamilnadu 623502, India

E-mail: nagarajansr@gmail.com

\section{R. Dhanasekaran}

Department of Electrical and Electronics Engineering,

Syed Ammal Engineering College,

Ramanathapuram, Tamilnadu 623502, India

E-mail: rdhanashekar@yahoo.com 